\title{
Investigações e explorações como parte do trabalho quotidiano na sala de aula ${ }^{1}$
}

\author{
João Pedro da Ponte² \\ Neusa Branco 3 \\ Marisa Quaresma ${ }^{4}$ \\ Arminda Azevedo ${ }^{5}$
}

\section{Resumo}

Este artigo apresenta três elementos fundamentais de unidades de ensino de cunho exploratório: (i) a conjetura de ensino-aprendizagem que preside à elaboração da unidade, (ii) as tarefas que a compõem; e (iii) os modos de trabalho, estilos de comunicaçãoe papéis deprofessor e alunos. Dá exemplos de três unidades de ensino de diferentes níveis de escolaridade que ilustram estes elementos e evidenciam os seus contributos para a aprendizagem. Nestas unidades de ensino predominam as tarefas de exploração e investigação possibilitando um ensino que promove o envolvimento ativo dos alunos na sua aprendizagem. Estas unidades favorecem também o trabalho com diversos tipos de representações, podendo os alunos usar representações próprias, e progredindo a partir daí para representações mais formais. A estrutura das aulas, com momentos de apresentação da tarefa, trabalho autónomo dos alunos e discussão coletiva e síntese, revela-se igualmente potenciadora do envolvimento dos alunos na sua aprendizagem e do desenvolvimento de diversos tipos de discurso na sala de aula.

Palavras-chave: investigações, ensino exploratório, unidades de ensino, tarefas, aprendizagem matemática,

\section{Abstract}

This article presents three key elements of teaching units of exploratory nature: (i) the teachinglearning conjecture that frames the development of the unit, (ii) the tasks that compose it; and (iii) the working modes, communication styles and roles or teacher and students. It gives examples of three teaching units of different levels of education that illustrate these elements and their contributions to the learning process. In these teaching units predominate investigation and exploration task teaching that promotes the active involvement of students in their learning. These units also favor working with different types of representations, and the students use their own representations, and progress from there to more formal representations. The structure of classes, with moments of presentation of the task, studentsautonomous work and collective discussion and synthesis also enhances the involvement of students in their learning and the development of various types of discourse in the classroom.

Key words: Investigations, Inquiry teaching, Teaching units, Tasks, Mathematics learning

\footnotetext{
${ }^{1}$ Este trabalho é financiado por fundos nacionais através da FCT - Fundação para a Ciência e Tecnologia no âmbito do Projeto Práticas Profissionais dos Professores de Matemática (contrato PTDC/CPE-CED/098931/2008).

2 Universidade da Georgia, EUA; Agregado em Educação, Universidade de Lisboa.

${ }^{3}$ Instituto de Educação da Universidade de Lisboa.

${ }^{4}$.Instituto de Educação da Universidade de Lisboa.

5 Instituto de Educação da Universidade de Lisboa.
} 


\section{Introdução}

A realização de investigações na sala de aula depende, antes de mais, da seleção de tarefas apropriadas (PONTE, BROCARDO\& OLIVEIRA, 2003). No entanto, uma tarefa de investigação isolada, apenas pode dar um contributo limitado para a aprendizagem dos alunos. Por isso, têm vindo a ser realizados estudos onde se dá atenção a unidades de ensino, compostas por conjuntos de tarefas, e que visam a aprendizagem de tópicos importantes do currículo de Matemática. Este artigodescreve as características destas unidades, que ilustra com exemplos de diferentes níveis de escolaridade, e faz um balanço dos seus contributos para o processo de ensino-aprendizagem.

\section{Unidades de ensino de cunho exploratório}

Numa unidade de ensino identificamos três elementos fundamentais: (i) a conjetura de ensino-aprendizagem que preside à elaboração da unidade, (ii) as tarefas que a compõem; e (iii) os modos de trabalho, estilos de discurso e papéis previstos para professor e alunos.É também necessário ter em atenção a avaliação dos alunos.

Tarefas. As tarefas são importantes, não em si mesmas, mas pela atividade que podem originar. Na verdade, aquilo que os alunos aprendem na aula de Matemática resulta principalmente da atividade que realizam e da reflexão que efetuam sobre essa atividade (CHRISTIANSEN\& WALTHER, 1986). O desenvolvimento de uma atividade matemática rica e produtiva por parte dos alunos pode basear-se em tarefas de natureza diversificada, como exercícios, problemas, investigações e explorações (PONTE, 2005). As tarefas estruturadas podem ser exercícios de desafio reduzido que visam sobretudo a consolidação de conhecimentos, ouproblemas de desafio elevado que visam a aplicação criativa dos conhecimentos que o aluno já possui. Pelo seu lado, as tarefas abertas podem ser exploraçõesde desafio reduzido que visam sobretudo a construção de novos conceitos, ouinvestigaçõesde desafio elevado que visam tanto o desenvolvimento de novos conceitos como o uso criativo de conceitos já conhecidos. O professor deve selecionar as tarefas de acordo com os objetivos definidos para cada aula, tendo em atenção a sua adequação aos alunos a que se destina.

Um aspeto muito importante das tarefas são os contextos. A distinção mais comum é entre contextos matemáticos e não matemáticos. No entanto, Skovsmose (2000) chama a atenção que, para os alunos, muitos contextos supostamente reais são, no fundo, artificiais chama-lhes contextos de "semi-realidade". Deve também notar-se que faz uma grande diferença trabalhar em contextos matemáticos com os quais temos familiaridade ou contextos matemáticos que nos são estranhos.

Outro aspeto, ainda, sãoas representações envolvidas. Bruner (1999) distingue entre representações ativas (objetos, movimentos do corpo), icónicas (imagens) e simbólicas. Muitas vezes, ao lado das representações formais ou até antes destas representações, há vantagem em trabalhar com representações informais. Estreitamente ligadas às representações estão os materiais a usar, quedeterminam em grande medida as representações admissíveis, incluindo materiais manipuláveis, novas tecnologias, etc.

Modos de trabalho, discurso e papéis na sala de aula. Na sala de aula podem usar-se diferentes modos de trabalho. Uma possibilidade é o modo coletivo, com o professor a interagir com todos os alunos e estes a interagir entre si. Outra é o trabalho em grupo e a 
pares, tendo em vista proporcionar aos alunos um ambiente estimulante de partilha. Deste modo, os alunos podem participar em dois níveis do discurso da aula - o coletivo e o privado, que desenvolvem com os seuscolegas. Usa-se também o trabalho individual, procurando desenvolver a capacidade de concentração e reflexão do aluno.

As aulas de cunho exploratório estruturam-se usualmente segundo três fases (PONTE, 2005): (i) a apresentação da tarefa e a sua interpretação pelos alunos (em coletivo); (ii) o desenvolvimento do trabalho pelos alunos (em grupos, pares ou individual); e (iii) a discussão e síntese final (em coletivo). Esta última fase é muito importante pois, segundo Bishop e Goffree (1986), é a ocasião mais apropriada para que sejam expostas conexões e significados, permitindo aos alunos relacionar ideias sobre vários temas, mostrando como as ideias matemáticas são naturalmente interligadas. Os momentos de discussão constituem oportunidades para negociação de significados matemáticos e construção de novo conhecimento. De acordo com o NCTM (2007),

A aprendizagem com compreensão poderá ainda ser aperfeiçoada através das interações na turma, à medida que os alunos sugerem ideias e conjeturas matemáticas, aprendem a avaliar o seu próprio raciocínio e o dos colegas, e desenvolvem capacidades de raciocínio matemático. Como tal, cada tarefa culmina sempre com um momento de discussão coletiva, como forma de refletir, discutir ideias, processos e conclusões (p. 23).

O discurso da sala de aula é unívoco, quando é dominado pelo professor, ou dialógico quando a contribuição dos alunos é reconhecida como importante.

Usualmente, é papel do professor propor as tarefas a realizar, estabelecer os modos de trabalho na sala de aula e dirigir o discurso. Contudo, o professor pode assumir em exclusivo o papel de autoridade matemática ou partilhá-lo com os alunos, caso em que procura estimular a sua capacidade de raciocínio e argumentação. O papel do aluno é sempre o de trabalhar nas tarefas que thes são propostas. Mas também pode variar na medida em que sentir que só deve intervir quando é solicitado ou, pelo contrário, deve intervir quando tem uma contribuição significativa para fazer.

Conjeturas de ensino-aprendizagem. Os documentos curriculares atuais, como o Programa de Matemática do Ensino Básico(ME, 2007) e as Normas do NCTM (2007) fornecem um conjunto de orientações gerais a ter em atenção. Por exemplo, relativamente às tarefas sugerem que os alunos devem ter experiências matemáticas diversificadas, incluindo explorações, investigações e problemas. Além disso, indicam que as tarefas devem envolver contextos matemáticos e não matemáticos e incluir outras áreas do saber e situações do quotidiano dos alunos, apresentadas de modo realista, de forma a capitalizar o seu conhecimento prévio.

Relativamente às representações, estes documentos indicam que os alunos devem compreender que existe uma variedade de representações para as ideias matemáticas e desenvolver a capacidade de passar informação de uma representação para outra. Indicam também que os alunos devem ser encorajados a criar as suas próprias representações (informais), como ponto de partida para a aprendizagem das representações matemáticas convencionais.

Quantoao discurso na sala de aula, estes documentos sugerem que o ensinoaprendizagem deve prever momentos para o confronto de resultados, discussão de estratégias e institucionalização de conceitos e representações matemáticas. Indicam, também, que o professor deve dar atenção aos raciocínios dos alunos, valorizando-os, procurando que eles os explicitem com clareza, que analisem e reajam aos raciocínios dos 
colegas. Recomendam, ainda, que ouvir, praticar, fazer, argumentar e discutir são atividades importantes na aprendizagem da Matemática.

Todas asunidades de ensino descritas a seguir, de um modo ou de outro, seguem estas orientações. Além disso, têm na sua base uma conjetura orientadora específica, chamada conjetura de ensino-aprendizagem, que constitui uma espécie de miniteoria que é posta à prova com a sua realização. Trata-se do pressuposto-chave que inspira a elaboração da unidade, e que pode respeitar à natureza das tarefas, ao respetivo contexto, aos modos de trabalho dos alunos, discurso e papéis na sala de aula, à articulação entre diferentes representações, ao uso de certos materiais, etc.

Avaliação dos alunos. A avaliação dos alunos numa unidade de ensino deve estar alinhada com os respetivos objetivos e conteúdos. Na concepção de uma unidade é usualfazer-se um levantamento aprofundado dos conhecimentos dos alunos, através de um processo de diagnóstico (usualmente um teste, entrevistas a alguns alunos ou ambos). No decorrer da unidade é frequente utilizar uma avaliação formativa tendo em vista apoiar o progresso dos alunos, diagnosticando problemas e insuficiências na sua aprendizagem e no seu trabalho (ME, 2007). Para isso são habitualmente considerados as apresentações e discussões orais das tarefas e as produções escritas dos alunos, quer na aula quer fora dela. Finalmente, a avaliação global na unidade pode revestir vários processos, sendo o mais comum a realização de teste escrito final (individual). A avaliação passa uma mensagem importante aos alunos, que pode reforçar ou desvirtuar a mensagem global transmitida pela unidade de ensino. Por isso, deve ser cuidadosamente considerada, a par da planificação da unidade.

\section{Comparação e ordenação de números racionais}

Os números racionais constituem um dos tópicos mais importantes do $2 .^{\circ}$ ciclo (correspondente à $5 .{ }^{a}$ e 6 . $^{a}$ séries) e é também um dos que mais dificuldades coloca aos alunos. Esta unidade de ensino visa a aprendizagem dos seguintes subtópicos do Programa de Matemática (ME, 2007): (i) Noção e representação de número racional; (ii) Comparação, ordenação e equivalência; e (iii) Percentagens. Para a sua lecionação foram previstos 9 blocos (de 90 minutos) para realização de tarefas e 1 bloco adicional para a realização de um teste de avaliação (para uma descrição detalhada da unidade de ensino ver Quaresma, 2010).

Ideias centrais.Para além da abordagem geral de cunho exploratório e investigativo, a unidade segue as indicações do programasegundo o qual os alunos devem desenvolver o sentido de número racional bem como a capacidade para utilizar o seu conhecimento para resolver problemas em contextos diversos. Para isso, devem compreender e ser capazes de usar propriedades e representações dos números racionais e apreciar a ordem de grandeza dos números.

A unidade contempla tarefas de natureza exploratória e problemas tendo em vista desenvolver o raciocínio matemático e a capacidade de resolução de problemas. Para isso, o trabalho na sala de aula valoriza o trabalho em grupo e em pares e os momentos de discussão coletiva. Além disso, assume as recomendações dainvestigação (CRAMER, POST\& CURRIER, 1993) e das orientações curriculares (ME, 2007; NCTM, 2007) que sugerem que o ensino deste tópico deve, nomeadamente: (i) enfatizar as inter-relações entre os vários significados de número racional (parte-todo, quociente, razão, medida e operador); (ii) contemplar os diferentes tipos de unidades e a respetiva construção; e (iii) promover a 
flexibilidade na conversão entre e dentro das várias representações de número racional (verbal, pictórica, decimal, fração, percentagem e reta numérica).

Para além do cunho exploratório e investigativo do trabalho realizado, uma ideia fundamental que está na base desta unidade é a de que o conhecimento dos números racionais passa pelo conhecimento das suas diferentes formas de representação (NCTM, 2007). Os alunos não só devem ser fluentes a usar as diversas representações, como devem ser capazes de passar facilmente de uma representação para outra e de decidir a representação a utilizar para resolver um problema.

As representações que assumem o papel chave são a fração e o numeral decimal. No entanto, é também bastante usada a representação pictórica e, além disso, usam-se numerais mistos e percentagens. Ao longo de toda a unidade, valorizam-se as estratégias intuitivas e informais dos alunos, bem como os seus conhecimentos anteriores. Assim, privilegiam-se os processos informais e as representações que os alunos já conhecem para a partir daí introduzir, gradualmente, novas representações formais de número racional (KIEREN, 1988; WEBB, BOSWINKEL\& DEKKER, 2008). Em particular, a representação dos números racionais parte de materiais concretos e usa com frequência representações pictóricas para levar os alunos à formalização dos conceitos. Contudo, a introdução das novas representações não significa o abandono de anteriores. Pelo contrário, os alunos podem continuar a usar as representações que conhecem, desenvolvendo flexibilidade para escolher a que é mais eficaz em cada situação.

A unidade de ensino tem por base uma conjetura de ensino-aprendizagem segundo a qual os alunos desenvolvem a sua compreensão de número racional e a sua capacidade de comparar e ordenar números racionais ao trabalharem em tarefasde natureza exploratória, usandoem simultâneo várias representações de número racional (com relevo para as frações, numerais decimais e representações pictóricas),num ambiente que valoriza as discussões coletivas.

A unidade começa (aula 1) por introduzir as diferentes representações de número racional, evidenciando as conversões entre elas. De seguida (aulas 2-4), propõe tarefas na representação decimal nos diversos significados, para relembrar conceitos já trabalhados nesta representação durante $011^{\circ}$ ciclo (da $1 .^{a}$ à $4 .^{a}$ série), como a comparação e ordenação, onde os alunos mostraram dificuldade no diagnóstico. Posteriormente, introduz as fraç̃̃es impróprias e os numerais mistos fracionários, como outra forma de representar números racionais, também nos diferentes significados. Nesta altura trabalha-se também a construção de partes e a reconstrução da unidade na representação fracionária (usando frações próprias e impróprias) e a percentagem (utilizando a representação pictórica como apoio para que os alunos possam visualizar as transformações). Esta abordagem inicial tem como principal objetivo desenvolver nos alunos o conceito de número racional e a noção de que estes números podem ser representados de diferentes formas, desenvolvendo flexibilidade nas conversões entre e dentro dessas representações.

Num segundo momento (aulas 5-9), são introduzidas tarefas relacionadas com comparação e ordenação de números racionais e equivalência de frações. Os alunos mostram habitualmente muitas dificuldades na comparação de frações que é aqui introduzida pela comparação entre pares de frações com numeradores iguais e com denominadores iguais. Pelo seu lado, a ordenação é realizada a partir de números representados em fração, decimal e percentagem. Inicialmente, são apresentadas frações simples que os alunos facilmente relacionam com outras representações. Seguidamente, é abordada a noção de frações equivalentes e é estudada a densidade dos números racionais. Para dar consistência ao trabalho de ordenação e comparação de números 
racionais, é introduzida a reta numérica. Finalmente, a unidade de ensino aborda ainda a percentagem como operador.

Uma tarefa de comparação e ordenação. A tarefa seguinte visava especificamente desenvolver a capacidade de comparar e ordenar números racionais.

A questão 1 é uma situação contextualizada que envolve grandezas contínuas no significado quociente. Pede aos alunos para partilhar equitativamente três pizas por quatro amigos e para comparar com a unidade a quantidade que cabe a cada um. A informação é dada verbalmente e não é indicada a representação a utilizar na resposta.

\section{Questão 1}

1.1. Quatro amigos foram a um restaurante e pediram três pizas. Dividiram igualmente as três pizas. Que parte da piza comeu cada amigo?

1.2. Cada amigo comeu mais que uma piza ou menos que uma piza? Explica o teu raciocínio.

\section{Questão 2}

2.1. Se em vez de quatro amigos fossem oito amigos, pedissem três pizas e as dividissem igualmente, que parte de piza comeria cada um?

2.2. Cada amigo comeu mais que uma piza ou menos que uma piza? Explica o teu raciocínio.

\section{Questão 3}

Em qual dos grupos anteriores, o de quatro amigos (Questão 1) ou o de oito amigos (Questão 2), cada amigo comeu mais piza? Explica o teu raciocínio.

Figura 1: Tarefa de comparação e ordenação

Os alunos mostram-se entusiasmados com esta questão, embora não disponham de um algoritmo para resolver. Começam por recorrer à representação pictórica, desenham as três pizzas, mas depois alguns não conseguem repartir as pizzas pelos quatro amigos. Nessa altura a professora sugere-Ihes que atribuam nomes às fatias e a maioria já consegue resolver o problema. É interessante verificar como uma precisão adicional (de carácter simbólico) na representação pictórica permite aos alunos raciocinar mais facilmente sobre a tarefa.

Alguns alunos não ficam apenas por esta representação, usando com a representação em fração, como mostra a resolução da questão 1 por Rui:

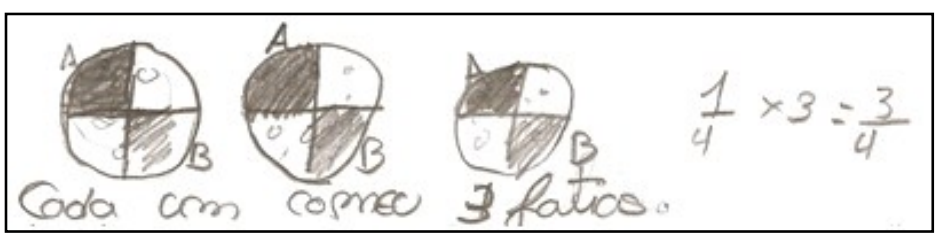

Professora: E depois fizeram mais alguma coisa?

Leonardo: Sim, fizemos contas.

Professora: Que contas fizeram?

Leonardo: Fizemos um sobre quatro...

Professora: Um quarto...

Leonardo: Vezes três é igual a três quartos. 
Estes alunos estendem às frações o seu conhecimento intuitivo dos números inteiros, uma vez que ainda não trabalharam formalmente a multiplicação entre um número racional e um número inteiro. Outros alunos, como Amélia e Leonor, fazem um raciocínio semelhante, em linguagem verbal, dizendo que cada parte representa $\frac{1}{4}$ da piza e, por isso, se cada um come três fatias, come $\frac{3}{4}$ da piza.

A segunda parte da questão 1 pede aos alunos que comparem a parte comida por cada amigo com a unidade. Alguns usam o conhecimento do dia a dia para responder:

Professora: Cada amigo comeu mais que uma piza ou menos que uma piza?

Turma: Menos.

Professora: Menos, porquê Leonor?

Leonor: Porque eles comeram só $\frac{3}{4}$ e uma piza inteira tem $\frac{4}{4}$.

André: Oh professora e não é só isso, vê-se logo porque se há 3 pizas eles são 4 não dá para comerem mais do que uma unidade.

Os alunos comparam a parte e o todo, tendo em atenção que o todo tem quatro partes e cada amigo só come três. Alguns, como Leonor, baseiam a sua argumentação na representação formal em fração, transformando a unidade numa fração de numerador e denominadorquatroecomparandodepoisosnumeradores. Outros, como André, usam apenas a linguagem verbal.

Mais adiante, a questão 3 pede aos alunos que comparem as partes obtidas nas questões anteriores. Trata-se, igualmente, de uma situação contextualizada com grandezas contínuas, mas envolvendo o significado medida. Nas questões anteriores os alunos tiveram oportunidade de comparar frações com denominadores iguais e esta questão envolve uma comparação entre frações com numeradores iguais e denominadores diferentes. Na discussão começou-se por estabelecer a relação entre o tamanho da parte que cabe a cada amigo nas duas situações $\left(\frac{3}{4}\right.$ e $\left.\frac{3}{8}\right)$ :

Professora: Qual a diferença entre aquilo que cada um come no primeiro caso e no segundo caso? O que é que se alterou?

Amélia: Foi que ficou partido em mais partes.

Professora: E o que é que aconteceu a cada parte?

Alunos: Ficou mais pequenino. Ficou a metade.

Leonor: Pois é, $\frac{3}{8}$ é metade de $\frac{3}{4}$ !

Professora: Quer dizer que cada um passou a comer que parte daquilo que comiam no primeiro caso?

Alunos: A metade.

Professora: Pois porque nós duplicámos o número de amigos, logo cada um teve de partilhar cada fatia com outro.

A partir das perguntas da professora, os alunos concluem que $\frac{3}{8}$ é metade de $\frac{3}{4^{\prime}}$ porque, como dizem, cada parte é metade da anterior. O facto de o contexto ser significativo para os alunos permite que eles cheguem por si próprios alunos à relação em causa.

Esta tarefa assume um carácter exploratório, pois os alunos não dispõem de processos rotineiros para responder às questões propostas. Têm, por isso, de inventar as suas estratégias, que passam sobretudo pela escolha de representações adequadas e de raciocínios sobre essas representações. De destacar, também, o papel da professora valorizando o conhecimento intuitivo dos alunos, incentivando a sua participação, sempre 
que possível com perguntas abertas (questões de inquirição) e, ao mesmo tempo, promovendo o desenvolvimento da sua linguagem matemática.

\section{Desenvolvendo a linguagem algébrica}

A Álgebra constitui um importante tema do programa de Matemática, nomeadamente a partir do $3 .^{\circ}$ ciclo do ensino básico (da 7. à 9. 9. séries). Esta unidade de ensino tem como objetivo promover o desenvolvimento do pensamento algébrico, procurando, em particular, desenvolver nos alunos: (i) a capacidade de analisar sequências, descrever relações e representá-las simbolicamente; (ii) a compreensão do conceito de variável e do significado dos símbolos, através do estudo de padrões e regularidades; (iii) a compreensão do significado das expressões algébricas e do significado do trabalho com expressões algébricas com base na análise de expressões equivalentes; e (iv) a capacidade de usar a linguagem algébrica, nomeadamente, equações, na resolução de problemas.A unidade inclui6 tarefas relativas ao estudo de sequências seguidas por 4 tarefas relativas a equações, tendo sido concretizada em35 tempos de 45 minutos (Para uma descrição detalhada da unidade de ensino ver Branco, 2008).

Ideias centrais. Durante muito tempo o ensino da Álgebra esteve centrado na manipulação simbólica, causando as maiores dificuldades aos alunos. Para resolver este problema, que Kaput (2008) designa como "thealgebraproblem", gerou-se um movimento tendo como ideia central o desenvolvimento do pensamento algébrico, envolvendo facetas como a generalização, a simbolização, o estudo de relações entre objetos matemáticos, a variação e a modelação (NCTM, 2007). Na verdade, a investigação mostra que os alunos, antes de tomarem contacto com os tópicos formais da Álgebra, já são capazes de pensar algebricamente em muitos aspetos (CARRAHER\& SCHLIEMANN, 2007).O professor pode então adotar metodologias que, partindo das estratégias informais dos alunos, proporcionem o desenvolvimento e a mobilização do pensamento algébrico como base para as aprendizagens mais formais da Álgebra.

A unidade de ensinoestá em consonância com os documentos curriculares atuais ( $M E$, 2007; NCTM, 2007) e apoia-se na investigação sobre as dificuldades dos alunos na aprendizagem da Álgebra (PONTE, BRANCO\& MATOS, 2009) e sobre o papel do estudo de sequências (ENGLISH\& WARREN, 1999; ZAZKIS\& LLILJEDAHL, 2002). Assim, foi valorizada a utilização da linguagem algébrica na generalização de relações e na resolução de problemas. Atendendo a estas orientações, as tarefas propostas nesta unidade procuram proporcionar oportunidades de aprendizagem diversificadas, pelo que têm um carácter problemático, exploratório e investigativo, promovendo a formulação de generalizações, a representação de números generalizados ou de grandezas incógnitas e variáveis, tal como sugerem Fiorentini, Miorim e Miguel (1993). As tarefas iniciais com sequências fomentam o surgimento da letra para representar quantidades desconhecidas e de expressões algébricas equivalentes que permitem a análise da transfromação simbólica de umas expressões noutras. No trabalho com equações usam a aprendizagem sobre a manipulação de símbolos proporcionada pelo contexto anterior. A dinâmica de aula procurou fomentar o trabalho individual e em pequenos grupos e a discussão coletiva. Para além das 10 tarefas indicadas, foram também realizados exercícios e problemas do manual adotado pela escola. Durante a concretização da unidade, a planificação inicial sofreu ajustes principalmente no que se refere ao tempo previsto para o desenvolvimento de algumas tarefas. Esta 
necessidade surgiu do grande empenho dos alunos, manifestado em diversas situações, e à profundidade da exploração realizada.

Deste modo, a conjetura de ensino-aprendizagem que está na base desta unidade é que o trabalho com sequências, em tarefas diversificadas,acompanhado por discussões coletivas, pode contribuir para o desenvolvimento e a capacidade de mobilização do pensamento algébrico dos alunos e, em particular, para a sua capacidade de realizarem generalizações e utilizar a linguagem algébrica, promovendo a sua compreensão das variáveis e equações.

Uma tarefa com sequências. Numa primeira aula desta unidade, os alunos trabalharam com sequências repetitivas. Na aula seguinte, a professora apresentou uma tarefa envolvendo uma sequência crescente (Figura 3).

Esta sequência tem características diferentes das que os alunos tinham trabalhado na aula anterior. Agora todas as figuras que constituem a sequência são diferentes e a sua forma depende da sua ordem. Esta é a primeira aula em que trabalham com sequências pictóricas crescentes. Os alunos representam, descrevem e generalizam as regularidades que encontram usando vários métodos. A generalização destas sequências pode surgir da análise de figuras consecutivas ou da identificação da relação entre o número de elementos que constitui uma figura e a sua ordem. É principalmente esta relação que a professora procura explorar, pois com ela surge, pela primeira vez, a utilização de símbolos.

1. Observem a sequência de figuras:

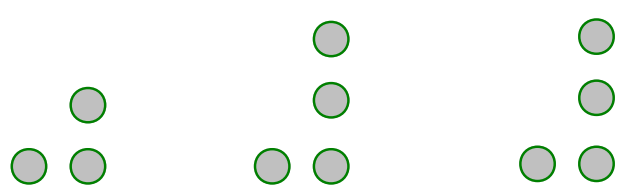

a) Desenhem a próxima figura da sequência.

b) Desenhem a 7. a figura da sequência. Quantas bolas tem a figura?

c) Sem desenhar, digam, justificando, quantas bolas tem a figura que ocupa a posição 14 da sequência?

d) Escrevam a sequência relativa ao número de bolas que tem cada uma das figuras até à posição 7 .

e) A que posição corresponde a figura que tem 19 bolas? Expliquem o raciocínio que efetuaram.

f) Descrevam como é construída qualquer figura desta sequência.

g) Escrevam uma expressão que represente o número de bolas que tem uma figura em qualquer posição.

Figura 2: Tarefa com sequência crescente

Em a), a figura que ocupa a primeira posição tem três bolas e as figuras seguintes obtêm-se acrescentando uma bola na vertical à figura anterior. Esta é a regularidade que os

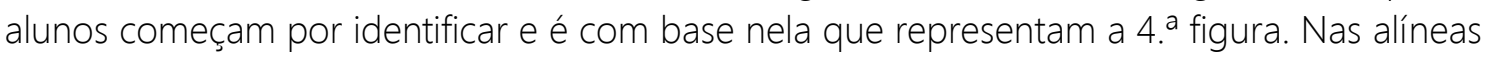
seguintes os alunos revelam uma outra interpretação da sequência. Identificam o que é comum a todas as figuras e verificam que o número de bolas da parte que se altera em cada figura está relacionado com a sua ordem. Assim, não necessitam de desenhar a sequência até à figura que pretendem para saber o número total de bolas que a constitui. Apenas sabendo a sua ordem conseguem determinar esse número, com base na regularidade que observam. Diversas respostas refletem esta generalização, como no caso de Mariana e Diana, em b): 


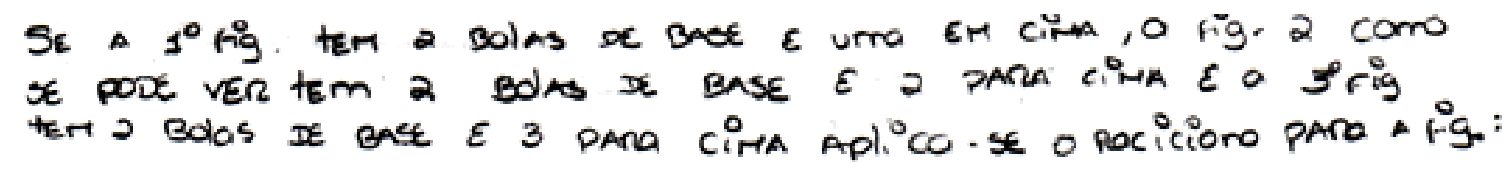

Mariana e Diana explicam como relacionam cada figura representada com a sua ordem e estabelecem o mesmo raciocínio para a figura de ordem sete. Também emc) alguns alunos indicam que, por se tratar da figura de ordem catorze, acrescentam catorze bolas às duas bolas da base.

Os alunos não mostram grande dificuldade em enunciar a regra de formação da sequência. Contudo, para a determinação de termos distantes, verificam quea estratégia recursiva não é a maiseficiente. Durante a discussão, Rafaela expressa a sua generalização algébrica, indicando a relação entre a ordem e o número de bolas necessário para representar a figura solicitada:

Susana - Professora, eu pus assim: Tem sempre duas bolas em baixo e aumento uma em cima de acordo com a sequência.

Professora - Sim. Mas isso é com base na anterior.

Susana - Sim.

Professora - Portanto se eu pedir a cinquenta tens de desenhar todas até à quarenta e nove para depois juntar mais uma bola?

Susana - Oh, professora. Tenho duas em baixo e depois aumento uma em cima.

Professora - Aumentas uma em cima com base em quê?

Susana - Com base na anterior.

Professora - Com base nas anteriores, era isso que estava a dizer. Se eu pedir a cinquenta não me digas que vais desenhar...

Susana - Não.

Professora - Como é que desenho, por exemplo, a figura vinte e cinco?

Rafaela - Faz duas bolas em baixo e depois vinte e cinco em cima.

Joana e Catarina são, tal como outros colegas, bastante sintéticas e não explicitam como estão distribuídas as bolas. A sua resposta, em f), revela já uma distanciação da situação concreta, não tendo de referir o valor da posição da figura na sequência, e a procura de uma fórmula geral que determina de modo direto o número de bolas, qualquer que seja a ordem:

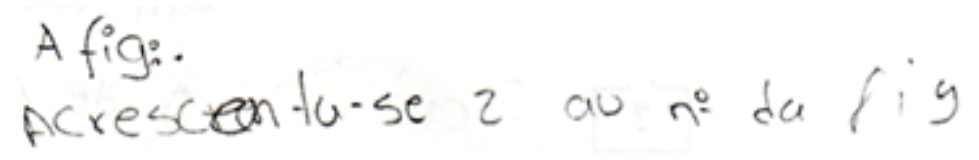

Com base na resposta a esta alínea, a professora procura que, com o contributo de toda a turma, se construa a expressão que representa o número de bolas de uma figura qualquer que seja a sua ordem. No entanto, surge desde logo a dúvida sobre o significado de "expressão". Antes representação simbólica, a professora questiona os alunos sobre como se pode determinar o número de bolas de uma figura. Susana consegue agora daruma descrição que a professora procura reforçar com alguns exemplos:

Professora - Eu tenho uma figura numa posição qualquer, como é que eu calculo o número de bolas que essa figura vai ter? 
Susana - Faz-se o número de bolas na vertical da figura e depois acrescenta-se duas bolas para fazer de base.

Professora - Se tiver, por exemplo, a figura dez. Quantas bolas vai ter?

Rafaela - Vai ter doze.

Professora - Como é que tu fizeste a conta?

Rafaela - É as duas bolas que ficam em baixo.

Xico e Ricardo registam alguns exemplos explorados na discussão coletiva:

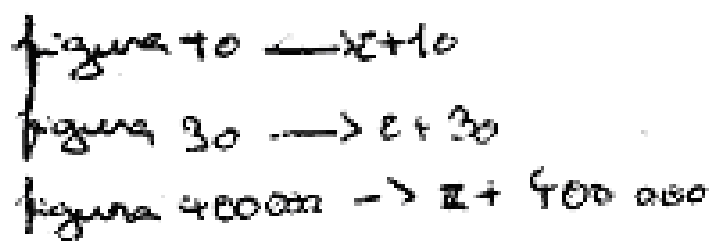

A análise destes exemplos contribui para a compreensão da generalização. No entanto, alguns alunos revelam ainda alguma dificuldade em expressá-la, referindo ser necessário especificar a ordem da figura da qual se pretende calcular o número total de bolas. Susana propõe, então, que a ordem da figura, como é desconhecida, seja representada por um símbolo, um ponto de interrogação:

Susana - Oh professora, já sei. Faz-se dois mais um ponto de interrogação.

Professora - Pode ser. Dois mais um ponto de interrogação. O que é que representa este ponto de interrogação?

Diana - É o número de bolinhas que temos de acrescentar.

Susana - É o numerozinho da figura porque a gente não tem número.

Professora - É o número da figura quando não temos número específico. Portanto, é a figura número...

Batista - Ponto de interrogação.

Professora - Portanto, a figura número ponto de interrogação, tem quantas bolinhas?

Susana - Duas mais ponto de interrogação.

O símbolo que Susana indica representa um número desconhecido que pode assumir diversos valores e do qual depende o número total de bolas da figura. Os alunos chegam, assim, a uma expressão geral que permite determinar o número de bolas que constitui qualquer figura. De seguida, a professora procura que os alunos percebam que podem usar outros símbolos, de acordo com a situação, com o mesmo significado. Batista, um aluno que frequenta pela segunda vez $07 .^{\circ}$ ano, sugere de imediato a utilização da letra $x$. Por sua vez, Susana refere poder usar $b, c$, ou $h$, letras já usadas anteriormente noutros contextos. Por fim, surge a letra $n$, como sendo o símbolo que os alunos consideram mais adequado para representar a ordem da figura. E Xico e Ricardo escrevem agora:

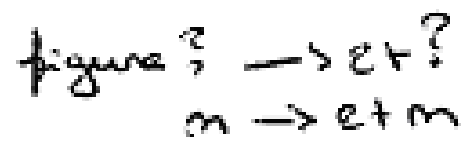

Esta situação promove a compreensão da generalização e proporciona a utilização da simbologia para a expressar. Assim, os símbolos para representar números desconhecidos (o ponto de interrogação e a letra) surgem de um modo natural e a utilização de expressões algébricas reveste-se de significado. 


\section{O estudo das funções polinomiais}

O conceito de função ocupa um lugar central no programa de Matemática do ensino secundário. Esta unidade de ensino, com 10 tarefas, refere-se ao tema Funções (10. ${ }^{\circ}$ ano) do Programa de Matemática $A(M E, 2001)$, sendo abordados os tópicos generalidades sobre funções, função quadrática, função módulo e funções polinomiais de grau superior a 2. As tarefas propostas visam proporcionar aos alunos experiências de aprendizagem significativas para o desenvolvimento do raciocínio matemático, promovendo diferentes formas de trabalho e a discussão na turma. Para a sua lecionação foram previstos 18 blocos (de 90 minutos), mais um bloco adicional para avaliação (para uma descrição detalhada da unidade de ensino ver Azevedo, 2009).

Ideias centrais. Esta unidade de ensino procura ter, tal como as anteriores, um forte cunho exploratório e investigativo. Seguindo as indicações do programa e de outros documentos de cunho curricular, como a brochura sobre funções (TEIXEIRA, PRECATADO, ALBUQUERQUE, ANTUNES\& NÁPOLES, 1997) e as Normas do NCTM (2007), procura tirarse amplo partido das possibilidades das novas tecnologias, nomeadamente as calculadoras gráficas.

Além disso, toda a unidade está orientada para o desenvolvimento do raciocínio matemático, assumindo que se trata de um objetivo fundamental do ensino desta disciplina. Assim, as tarefas propostas visam proporcionar aos alunos experiências de aprendizagem significativas para o desenvolvimento do raciocínio, promovendo o trabalho individual, em pares e em pequenos grupos, bem como a discussão na turma. Ao longo da unidade trabalha-se sempre com representações algébricas e representações gráficas das funções em estudo, em estreita ligação entre si (HITT, 1998). Muitas vezes, dá-se também atenção aos valores numéricos.

A planificação da unidade, para além de investigações e explorações, inclui igualmente exercícios e problemas do manual escolar adotado pela escola, considerando a importância da diversificação de tarefas na aprendizagem e visando a consolidação de conhecimentos adquiridos. Os exercícios e problemas escolhidos são de diferentes níveis de dificuldade, permitindo aos alunos pôr em prática os conhecimentos que vão adquirindo e conduzindo a uma melhor compreensão dos conceitos. Na seleção de tarefas também é tido em conta o contexto, sendo algumas de cunho estritamente matemático, enquanto outras se referem a situações da realidade. A inclusão destas situações reais assenta na ideia que, a partir delas,os alunos podem dar um maior significado às ferramentas matemáticas que estão a aprender.

Tal como nas unidades de ensino anteriores, a realização das tarefas na sala de aula passa por norma por três fases: (i) a apresentação da tarefa, (ii) o desenvolvimento do trabalho por parte dos alunos; e (iii) a discussão do trabalho realizado, com uma síntese final.Na realização das tarefas os alunos trabalharam em grupos (em 3 momentos), em pares (10 momentos) e individualmente (11 momentos). Além disso, realizaram relatórios escritos em 5 tarefas (3 individuais e 2 em pares). É de notar que a calculadora gráfica assume um papel fundamental na exploração das tarefas propostas, para visualizar os efeitos dos diversos parâmetros, testar conjeturas e passar de uma representação para outra (KISSANE, 2001). Mas os seus resultados são sempre confrontados com a resolução analítica, enfatizando desta forma o trabalho com as diferentes representações de funções, bem como as conversões entre elas. Para a familiarização dos alunos com as potencialidades da calculadora gráfica foi utilizado o viewscreen. 
A conjetura de ensino-aprendizagem subjacente a esta unidade é que a resolução de problemas e a realização de tarefas de carácter investigativo, com recurso à calculadora gráfica, com elaboração de relatórios escritos e discussões coletivas, podem contribuir não só para a aprendizagem dos conceitos relativos a funções mas também para 0 desenvolvimento do raciocínio matemático dos alunos.

Tarefa: Investigando funções cúbicas ${ }^{6}$. Trata-se da sétima tarefa do conjunto de 10 que compõem esta unidade de ensino. Esta tarefa visa, especificamente, levar os alunos a (i) descobrirem relações entre conceitos; (ii) formularem generalizações a partir de experiências; (iii) validarem conjeturas; e (iv) comunicarem conceitos, raciocínios e ideias, oralmente e por escrito, com clareza e rigor lógico.

Esta tarefa, para a qual foi solicitado um relatório individual, serviu de introdução às funções polinomiais de grau superior a dois, em particular, ao estudo da família de funções cúbicas. Tinha uma primeira parte com questões sobre funções cúbicas dadas gráfica e algebricamente e, numa segunda fase, pretendia que os alunos explorassem os possíveis aspetos que estas funções podem tomar. $O$ enunciado desta parte era o seguinte:

Investiga:

Quais serão os possíveis aspetos de uma função definida por um polinómio do 3. grau?

Figura 3 - Tarefa "Investigando funções cúbicas" (2. ${ }^{\text {a fase) }}$

De um modo geral, os alunos perceberam a importância de estudar casos particulares com vista a uma generalização. A maioria dos alunos explorou vários casos particulares, utilizando a calculadora gráfica, alterando os valores dos vários parâmetros desta família de funções e identificando regularidades. Alguns alunos conjeturaram e testaram relações que permitissem compreender os efeitos desses parâmetros no comportamento gráfico das funções.

António é um dos alunos que mais se evidencia ao longo da unidade, revelando aptidão para formalizar algebricamente as suas conjeturas. Após confirmar que a função dada graficamente poderia ser, de facto uma função cúbica e ter feito estudo correto das funções cúbicas dadas algebricamente, realiza a investigação proposta sobre os possíveis aspetos de uma função cúbica, apresentando o seguinte relatório:

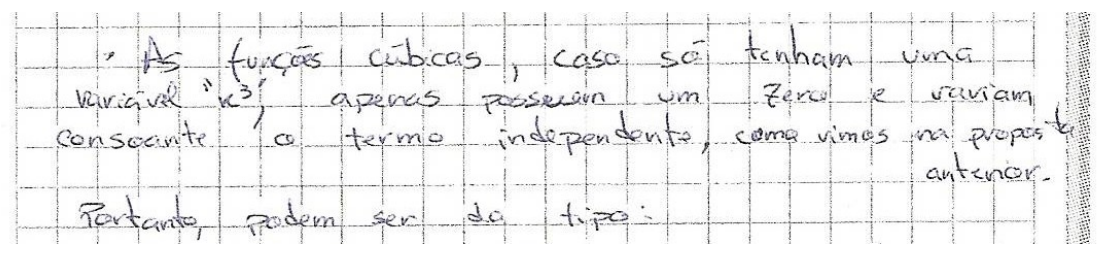

${ }^{6}$ Adaptado de "Infinito 10 A", Areal Editores. 

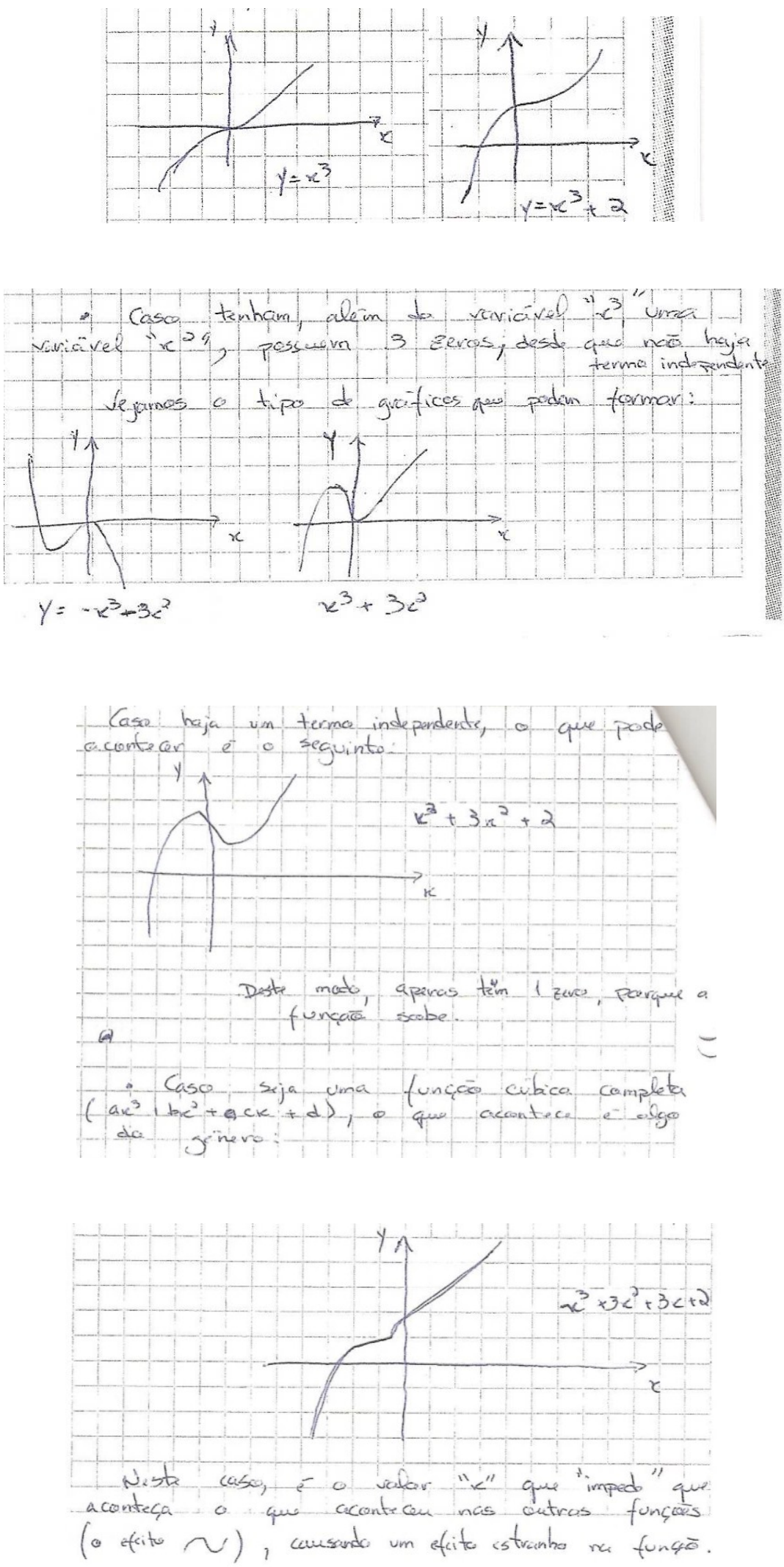

António revela a preocupação de explorar alguns casos particulares antes de proceder a uma generalização sobre a influência dos vários parâmetros no comportamento gráfico das funções. Mostra, ainda, a preocupação de encontrar uma justificação plausível para as conclusões que retira por observação das transformações. Apesar de ter realizado uma boa exploração da tarefa, considera que foi difícil tentar encontrar todos os aspetos possíveis de 
uma função cúbica: "Não achei muito difícil, até correu bem, se bem que a última parte, a dos vários aspetos, era difícil encontrar todos..."

Apesar de ter apresentado, no início da unidade, dificuldades esporádicas na formulação de conjeturas e respetiva formalização, António manifestou claramente nesta tarefa a sua facilidade em trabalhar com formalizações algébricas. É de sublinhar o modo como tentou ultrapassar as suas dificuldades, como foi o caso da tarefa 4, "À volta com investigações de funções quadráticas", na qual António conseguiu encontrar uma relação entre a intersecção com os zeros das retas e das parábolas, mas quanto à intersecção com o eixo dos yyconjeturou uma expressão que, como continha um erro, não conseguiu confirmar e teve de refutar.

No seu trabalho nesta quarta tarefa, António não consegue confirmar a sua fórmula para os exemplos apresentados, nem consegue encontrar outro modo de resolver a questão. No final da unidade reconhece as suas dificuldades na resolução desta tarefa. Recorda que testou a expressão que escreveu, mas não conseguiu confirmá-la. Equaciona uma estratégia alternativa de a abordar, tendo em conta as ferramentas entretanto adquiridas durante a unidade:

\begin{abstract}
Houve uma [tarefa] que foi muito difícil, era um relatório individual, foi no 1. ${ }^{\circ}$ período... [Começa a observar as tarefas] A 1 foi fácil, a 2 também, a 3 também foi mais ou menos fácil... [olha para a 4] Foi esta. Consegui escrever as equações das parábolas todas, respondi aos outros problemas e tentei dar a volta, mas não consegui encontrar as funções afins cujo produto desse as parábolas. Ainda arranjei uma expressão, mas não consegui confirmá-la para todos os valores. Mas agora acho que já conseguia de outra maneira, porque se eu comparasse os sinais e os zeros já chegava lá melhor...Mas na altura achei mesmo muito difícil..
\end{abstract}

No final da unidade de ensino, António mostra grande desembaraço a lidar com questões de Matemática, formulando conjeturas e procurando testá-las. Revela também uma boa compreensão dos conceitos matemáticos envolvidos no estudo de funções quadráticas. De sublinhar o modo como a professora combina o trabalho individual com o trabalho de grupo, e a sua valorização da comunicação escrita que leva António a produzir relatórios como o acima transcrito.

Os resultados desta experiência sugerem que os problemas contextualizados contribuem para uma aprendizagem, com significado, das funções. $\bigcirc$ uso da calculadora gráfica permitiu o confronto permanente das várias formas de representar funções, contribuindo para uma melhor compreensão das funções e das suas propriedades. As tarefas de exploração e investigação contribuíram para desenvolver capacidades como a identificação de regularidades e a formulação, teste e justificação de conjeturas. Os relatórios escritos e as apresentações orais contribuem para o desenvolvimento das capacidades de comunicar matematicamente e de justificar processos e as discussões e reflexões sobre as tarefas permitem a clarificação de ideias intuitivas e alargam o leque de estratégias dos alunos.

\title{
Conclusão
}

As unidades de ensino acima referidas têm por objetivo testar conjeturas de ensinoaprendizagem e, desse modo, construir novo conhecimento acerca dos processos de aprendizagem dos alunos. No estudo sobre os números racionais foi possível verificar que 
os alunos desenvolveram a sua compreensão destes números e a sua capacidade de comparar e ordenar números racionais ao trabalhar em simultâneo com diferentes representações. Os alunos desenvolveram a sua compreensão das frações tendo por base os seu conhecimento prévio intuitivo relativo aos diversos significados de número racional e às representações pictóricas, decimal e percentagem. Deste trabalho resultam novas questões por responder, relativas à articulação entre representações e raciocínio formal e informal, representação na reta numérica, reconstrução da unidade e aprendizagem das razões, a estudar em trabalhos futuros.

O estudo sobre o desenvolvimento do pensamento algébrico evidencia que o trabalho com sequências, em tarefas diversificadas, apoia o desenvolvimento e a capacidade de mobilização do pensamento algébrico dos alunos. Estes desenvolveram a sua capacidade de realizar generalizações e de as expressar simbolicamente. Além disso, têm mais facilidade que o habitual no estudo inicial das equações, manifestando compreender o significado dos símbolos e a simplificação de expressões. O problema é que o domínio da linguagem algébrica não depende apenas da fase de iniciação. Para se apropriarem verdadeiramente desta linguagem os alunos precisam de percorrer um longo caminho de experiências algébricas, com objetos sofisticados como equações, expressões e funções, em relação aos quais há que construir e experimentar novas unidade de ensino.

Também a conjetura de ensino-aprendizagem subjacente à unidade das funções polinomiais é corroborada pelos resultados obtidos. Para alunos como António, a resolução de problemas e a realização de tarefas de carácter investigativo, com recurso à calculadora gráfica, contribuem para a aprendizagem dos conceitos relativos a funções e também para o desenvolvimento do raciocínio matemático. O problema é que neste nível de ensino existem alunos com sérias deficiências de domínio da linguagem algébrica e, para eles, será necessário conceber e experimentar outros percursos de ensino-aprendizagem.

Em todas as unidades de ensino apresentadas as tarefas de exploração e investigação assumem um papel proeminente. Trata-se de tarefas com um papel essencial num ensino que procura promover o envolvimento ativo dos alunos na sua aprendizagem. Em todas as unidades se usaram contextos matemáticos e não matemáticos, em combinações que se revelaram ajustadas. Os dois tipos de contexto parecem necessários para desenvolver nos alunos uma perspectiva correta da Matemática e como pode ser usada em situações reais. O mais importante nos contextos não parece ser a sua relação com a vida diária dos alunos mas o facto de eles estabelecerem com facilidade uma relação de desafio e envolvimento com o que lhes é proposto. Em todas as unidades indicadas se recorreu a diversos tipos de representações, estimulando os alunos a usar aquelas em que se sentem à vontade e a desenvolverem, quando necessário, as suas próprias representações.

Em todas as unidades referidas se estruturaram as aulas em três momentos principais, a apresentação/negociação das tarefas, o trabalho autónomo dos alunos, e a discussão coletiva e síntese final. Esta estrutura permite o desenvolvimento de diversos tipos de discurso, em especial o discurso de natureza dialógica, e favorece o assumir o papel de autoridade matemática por parte dos alunos. Trata-se, portanto, de uma estrutura de aula que há que continuar a usar em trabalhos futuros, procurando perceber como otimizá-la.

A construção e experimentação deste tipo de unidades de ensino, tanto nos primeiros anos, como nos níveis intermédios e até nos ensinos secundário e superior, tem permitido aprofundar o conhecimento dos processos de aprendizagem dos alunos e tem gerado inúmeros materiais e recursos para os professores. Na sua base está a ideia do trabalho investigativo e exploratório, devidamente enquadrado numa perspectiva curricular sobre a aprendizagem da Matemática. 


\section{Referências}

AZEVEDO, A. B. G. O desenvolvimento do raciocínio matemático na aprendizagem das funções: Uma experiência com alunos do ensino secundário, 2009. Dissertação de mestrado, Universidade de Lisboa. Disponível no Repositório da UL.

BISHOP, A.; \& GOFFREE, F. Classroom organization and dynamics. In: CHRISTIANSEN, B., HOWSON, A. G. \& OTTE, M. (Eds.), Perspectives on mathematics education (pp. 309-365). Dordrecht: D. Reidel, 1986, P. 309-365.

BRANCO, N. O estudo de padrões e regularidades no desenvolvimento do pensamento algébrico, 2008. Dissertação de mestrado, Universidade de Lisboa. Disponível no Repositório da UL.

BRUNER, J. Para uma teoria da educação. Lisboa: Relógiod'Água, 1999.

CARRAHER, D. W.;\& SCHLIEMANN, A. D. Early algebra and algebraic reasoning. In: LESTER, F. (Ed.), Second handbook of mathematics teaching and learning. Greenwich, CT: Information Age, 2007, P. 669-705.

CHISTIANSEN, B.;\& WALTHER, G. (1986).Task and activity. In: CHRISTIANSEN, B., HOWSON, A. G. \&OTTE, M. (Eds.), Perspectives on mathematics education. Dordrecht: D. Reidel, 1986, P. 243-307.

CRAMER, K.; POST, T.;\& CURRIER, S. Learning and teaching ratio and proportion: Research implications. In:OWENS, D. T. (Ed.), Research ideas for the classroom: High school mathematics. Reston: NCTM, 1993, p. 159-178.

ENGLISH, L.;\& WARREM, E. Introducing the variable through patterns exploration. In: MOSES, B. (Ed.), Algebraic thinking, grades K-12. Reston, VA: National Council of Teachers of Mathematics, 1999, p. 141-145.

FIORENTINI, D.; MIORIM, M. A.;\& MIGUEL, A. Contribuição para repensar a educação algébrica elementar. Pro-Posições, 4, n. 1, 1993, 78-90.

HITT, F. Difficulties in the articulation of different representations linked to the concept of function. The Journal of Mathematical Behavior, 17, n. 1, 1998, 123-134.

KAPUT, J. J. (2008). What is algebra? What is algebraic reasoning? In: KAPUT, J. J.;CARRAHER, D. W. \&BLANTON, M. L. (Eds.), Algebra in the Early Grades. New York, NY: Routledge, 2008, p. 5-17.

KIEREN, T. Personal knowledge of rational numbers: Its intuitive and formal development. In: HIEBERT, J. \&BEHR, M. (Eds.), Number concepts and operations in the middle grades. Reston: NCTM, 1988, p. $162-181$.

KISSANE, B. Technology and the curriculum; the case of the graphics calculator. In: THOMAS, M. O. J. (Ed.), Proceedings of Time 2000: An international conference on technology in mathematics education (pp. 60-71). Auckland, NewZealand, 2001, p. 60-71.

MINISTÉRIO DA EDUCAÇÃO. Matemática A - 10. a ano. Lisboa: ME-DES, 2001.

MINISTÉRIO DA EDUCAÇÃO. Programa de Matemática do Ensino Básico. Lisboa: ME-DGIDC, 2007.

NCTM. Princípios e normas para a Matemática escolar. Lisboa: APM, 2007.

PONTE, J. P. Gestão curricular em Matemática. In: GTI (Ed.), O professor e o desenvolvimento curricular. Lisboa: APM, 2005, p. 11-34.

PONTE, J. P., BRANCO, N., \& MATOS, A. Álgebra no ensino básico. Lisboa: DGIDC, 2009.

PONTE, J. P.; BROCARDO, J.;\& OLIVEIRA, H. Investigações matemáticas na sala de aula. Belo Horizonte: Autêntica, 2003. 
QUARESMA, M. (2010). Ordenação e comparação de números racionais em diferentes representações: uma experiência de ensino, 2010. Dissertação de mestrado, Universidade de Lisboa. Disponível no Repositório da UL.

SKOVSMOSE, O. Cenários para investigação. Bolema, 14, 2000, 66-91.

TEIXEIRA, P.; PRECATADO, A.; ALBUQUERQUE, C.; ANTUNES, C.;\& NÁPOLES, S. Funções-10ª ano de escolaridade. Lisboa: Ministério da Educação, Departamento do Ensino Secundário, 1997.

WEBB, D.; BOSWINKEL, N.; \& DEKKER, T. Beneath the tip of the iceberg: Using representations to student understanding. Mathematics Teaching in the Middle School, 14, n. 2, 2008, 110-113.

ZAZKIS, R.; \& LILJEDAHL, P.Generalization of patterns: The tension between algebraic thinking and algebraic notation. Educational Studies in Mathematics, 49, 2002, 379-402. 